\title{
Hackathons as Instruments for Settlement Sector Innovation
}

Eliana Trinaistic, MCIS Language Solutions, Canada

\begin{abstract}
In Canada, the non-profit organizations (NPO) and settlement sectors are increasingly reexamining their responsibility for service delivery and service design. With a growing interest in understanding how to include design principles and an "innovation" mindset in addressing the long-term outcomes of social services, new instruments are introduced as a way to experiment with different modes of engagement among the various stakeholders. The aim of community hackathons or civic hacks-a derivative of tech gatherings customized to fit public engagementis to collaboratively rethink, redesign, and resolve a range of social and policy issues that communities are facing, from settlement, the environment, health, or legal services. Although hackathons and civic hacks aspire to be democratic, relationship-driven instruments, aligned with non-profit principles of inclusion and diversity, they are also risky propositions from the perspective of the non-profit organizational culture in Canada in that they tend to lack solid structure, clear rules, and fixed outcomes. Despite the challenges, the promise of innovation is too attractive to be disregarded, and some non-profits are embarking (with or without the government's help) on incorporating hackathons into their toolkits. This case study will present a practitioner's perspective on the outcomes of two community hackathons, one exploring migration data sets and the other on language policy innovation, co-developed between 2016 and 2019 by MCIS Language Solutions, a Toronto based not-for-profit social enterprise, in partnership with various partners. The case study examines how the hackathon as an instrument can aid settlement sectors and governments in fostering non-profit innovation to rethinking the trajectory of taking solutions to scale.
\end{abstract}

Keywords: hackathon; non-profit; settlement sector; social innovation

Publication Type: case study

\section{Introduction}

0 ver the past few years, the government of Canada has shown a continued interest in accelerating innovation in social and non-profit organizations (NPO). From establishing the Canadian Social Innovation and Social Finance Strategy steering group in 2017 (Employment and Social Development Canada, 2018) to setting up a Senate-appointed special committee on the charitable sector with the task of examining "the impact of federal and provincial laws and policies governing charities, non-profit organizations, and other similar groups" (Blumberg, 2018), the government set up the stage with a $\$ 755 \mathrm{M}$ Social Finance Fund for charitable, non-profit, and social purpose organizations, aimed at implementing "innovative ideas, and connect with non-government investors seeking to support projects that will drive positive social change" (Government of Canada, 2018, p. 38). The 2018 Innovation, Science and

The International Journal of Information, Diversity, \& Inclusion, 4(2), 2020

ISSN 2574-3430, https://jps.library.utoronto.ca/index.php/ijidi

DOI: 
Economic Development of Canada (ISED) report "Building a Nation of Innovators" defined sector innovation as a partnership-driven approach between NPOs and a range of partners including the industry, post-secondary institutions, and provinces and territories. The aim is to focus on research and development (R\&D) collaboration that is "larger in scale, scope, and longevity than was often the case in the past" (Innovation, Science and Economic Development Canada (ISED), 2019, p. 55).

This surge of interest around making the case for a nationwide innovation agenda inspired some NPOs to test new models of engagement, often mimicking the tech sector design and prototyping, while hoping to understand the scope of innovation. Broadly speaking, the scope of industry innovation is loosely defined by the Oslo Manual (OECD/Eurostat, 2019), and includes four organizational areas: culture, resources, products/services, and processes. In January 2019, while gathering feedback on sector innovation, the insights provided were clearly articulated (Senate Canada, 2019). To support the culture of innovation, the sector suggested "embedding innovation" and "having the agency" of a designated role or department. Data sharing was also identified as a primary innovation resource needing to be managed by public trusts, while products/services innovation was identified as ideal opportunities for participatory design and wider collaboration (e.g., implementing hackathons or similar methodologies). MCIS, which stands for Multicultural Community Interpreter Services, is a service delivery driven NPO that specializes in facilitating language access to critical services. Their earlier attempts to bring hackathons to fruition was due to the absence of a mandate, budgetary constraints, insufficient access to partners in the civic tech community, and relevant data sets (Trinaistic, 2018).

The purpose of a hackathon (a portmanteau of "hacking marathon"), which has been a tool of the tech industry since the early 1990s, is to explore alternatives to existing design solutions and business as usual processes while promoting collaboration. Unlike technical hackathons-seen as a recommended part of career preparation, recruitment fairs, and an exercise in demonstrated readiness of young graduates with technical backgrounds to "netWORK" (Nardi et al., 2002)community hackathons, sometimes interchangeably used with civic hacks, are considered to be "a subset of this trend that bring together ad hoc groups under the auspices of conceiving and prototyping technologies to address social conditions and concerns" (Lodato \& DiSalvo, 2016). Being less about the technology, project pitches, and semi-finished products and more about conversations and bringing together a spectrum of people with varied professional and lived experiences, these events are meant to brainstorm on and crowdsource alternative solutions and facilitate participation by making all voices count and contribute equally. The European Commission's "Quality of Public Administration Toolbox for Practitioners" suggests that hackathons or civic hackings are, in effect, methodologies that aim at "quickly improving the processes and systems of local government with new tools or approaches... (and) as an act of citizenship in the belief that government can work for the people, by the people in the 21st century" (European Commission, 2017, p. 50).

Based on the data MCIS gathered through informal interviews and the survey of hackathon participants (primarily from non-profit sector across Ontario) in 2019,1 it is apparent that NPOs are polarized in their views of hackathons/civic hacks either as "interesting" and "promising" or "confusing" and "irrelevant." Amongst reasons for such difference in responses are generational biases, swaying between reluctance in perceiving the usefulness of this model versus excited expectations around hackathon-based style of collaborative learning. Also, some participants are inclined to reject disrupted project management flow while others embrace non-linear prototyping and experimenting. For some, the lack of clear outcomes is distressing. For others,

The International Journal of Information, Diversity, \& Inclusion, 4(2), 2020

ISSN 2574-3430, jps.library.utoronto.ca/index.php/ijidi/index

DOI: 
the ambiguity of "unfinished solutions" is wholeheartedly embraced as a tool of disrupting the business as usual. For these reasons, hackathons could be a disappointing experience for participants who are used to more structured engagement and support of the academia-and of students in particular-could be crucial in creating connections between more traditional, project management-fixed, and outcomes-heavy approaches and experiment-driven, agile, and flexible opportunities.

\section{Migration Data Hackathon (MigrahackTO)}

\section{The Rationale}

In addition to providing services to beneficiaries, NPOs are chief public data harvesters. The notion of having standardized datasets for better sharing among and across sectors has been permeating the innovation discourse for a decade now (Ontario Nonprofit Network, 2015). Mowat Centre reports, "Bridging the Gap" (Cave et al., 2017) and "Collaborating for Better Impact" (Cave et al., 2018), have suggested that data sharing along with an integrated data ecosystem is what the sector needs to be able to fully understand its own context. Similarly, Lalande et al. (2018) notice that

[T] he non-profit sector has a wealth of data on social issues such as homelessness, poverty reduction, criminal justice, and mental health, [and] it is important to acknowledge that data, by itself, is often not meaningful until it is analyzed and understood within a "data ecosystem" ... processed, analyzed, contextualized, and translated so that it is useful to both policymakers and practitioners. (para 4)

In the case of language services provision, for example, the data that speaks about beneficiariespeople with language barriers, customers or service providers interacting with beneficiaries, and language professionals or interpreters and translators facilitating interactions in courts, hospitals, or legal clinics-can be only understood if additional datasets about the broader services ecosystem (e.g., shelters, police, health, legal, and educational sectors) can be cross referenced (Cave et al., 2018).

In some respects, Canada is still struggling with a lack of clear guidance on effectively using public digital infrastructure. On the one hand, pressures to innovate touts sharing as a panacea; on the other, without clear data sharing policy, NPOs are afraid that the digital rights of their users-newcomers and refugees in particular-will be at risk of breach and that these marginalized populations will become further marginalized. Clearly, the complex constraints of the business of settlement sector innovation cannot be addressed by technology alone.

In the given context, the objectives of MigrahackTO, the Toronto version of immigration-related hackathons that were held in several American and European cities, 2 were to provide a sandbox for the immigration and settlement sector to ask questions such as: how might we collaborate if we could safely share our administrative data? How might we define innovation, if the definition were to be determined by us? MCIS, who spearheaded the MigrahackTO, was also interested in finding out whether hackathons could facilitate partnerships with academia and government agencies, as well as how evidence-based storytelling could turn the attention toward clients' narratives. Lastly, the question of whether there was a much broader role that NPOs could play in initiating conversations on NPO innovation was also on the table.

The International Journal of Information, Diversity, \& Inclusion, 4(2), 2020

ISSN 2574-3430, jps.library.utoronto.ca/index.php/ijidi/index

DOI: 


\section{The Process}

MigrahackTO (Migration Hackathon Toronto) took place at the Mozilla office in Toronto. It welcomed over 35 participants from the settlement and civic tech sectors, as well as journalists and academics. The event began with an orientation session, followed by a series of data visualization and storytelling workshops over the next couple of days, and ended with project showcases and a town hall discussion. The focus was on learning about data visualization and creating corresponding narratives with the help of facilitators. Mentors from government and civic tech provided advice and support to participants while journalists advised on media framing and public relation strategies. The town hall allowed participants to highlight what worked and what did not work so well and provided substantial input on how this work can be continued. The proceedings from MigrahackTO were compiled into a report and subsequently published and disseminated widely (MCIS Language Solutions, 2018).

Table 1. Types of Audiences and Activities Undertaken Before, During and After MigrahackTO Hackathon

\begin{tabular}{ll}
\hline Participants & Pre-event Participation \\
\hline $\begin{array}{l}\text { NPOs: settlement sector, shelters, NPO data } \\
\text { entry staff }\end{array}$ & $\begin{array}{l}\text { Connect in advance in-person to introduce } \\
\text { project and solicit data sets } \\
\text { End users: represented by interpreters and } \\
\text { translators }\end{array}$ \\
$\begin{array}{ll}\text { Academia: student volunteers, journalists, data } \\
\text { scientists }\end{array}$ & Sought academia help in soliciting \\
$\begin{array}{l}\text { Government and policy makers } \\
\text { Civic tech community }\end{array}$ & Partner \\
\end{tabular}

Event

\begin{tabular}{|c|c|c|}
\hline Day 1 & Day 2 & Day 3 \\
\hline $\begin{array}{l}\text { Evening: } \\
\text { - Orientation: } \\
\text { purpose, objectives } \\
\text { and outcomes }\end{array}$ & $\begin{array}{l}\text { Morning: } \\
\text { - Workshops } \\
\text { O Infographics: Data } \\
\text { visualization and } \\
\text { storytelling } \\
\text { DataViz: A practical guide } \\
\text { to designing with data } \\
\text { and open software } \\
\text { Mapping/Google Data } \\
\text { Boot Camp } \\
\text { - Forming Teams }\end{array}$ & $\begin{array}{l}\text { Morning: } \\
\text { - Continuing work on projects } \\
\text { - Optional Workshops } \\
\text { ○ Census Database for } \\
\quad \text { Journalists } \\
\text { Got Data? Requesting } \\
\text { through the Access to } \\
\text { Information Act } \\
\text { Afternoon: } \\
\text { - Project show and tell } \\
\text { - Debrief }\end{array}$ \\
\hline
\end{tabular}

The International Journal of Information, Diversity, \& Inclusion, 4(2), 2020

ISSN 2574-3430, jps.library.utoronto.ca/index.php/ijidi/index

DOI: 
Afternoon:

- Work on projects overseen by mentors

Post-event

- Creation of data base of data sets

- Creation of data base of projects

- Creation of final report

\section{Challenges}

In looking back, it can be said that the greatest challenge for the MigrahackTO organizers was in the assumption that if the technical skillsets are addressed first, the "lived" experiences will subsequently naturally fill the gaps by informing the technology about genuine service needs. For this reason, prior preparation for participants was minimal and informal, which, in retrospect, may have hindered the ability of some participants to contribute as much as they would otherwise have. Next, unlike instruments conventionally employed in the settlement sector, such as focus groups or facilitated conversations, hackathons are largely based on the model of self-learning and self-affirmation and thus perhaps better suited for those gravitating toward research and technology fields than public-facing work. To balance the self-learning component, the organizers peppered the day with story-sharing breakouts and short video segments as a means of creating more opportunities for shared reflections and conversations.

\section{The Shift}

Based on the notes taken by organizers and volunteers during the event, participants seemed to have acquired an increased confidence in interacting with-if not mastering-data visualizations, while it was clearly a cause for concern for the majority of participants at the beginning of the event. By the end of the event, the focus had clearly shifted away from acquiring technical skills and toward an involved conversation about advocacy for clients' digital rights. The closing town hall conversations shed light on the two primary innovation drivers in the settlement sector: "respect and care for the users of services" and "advocating for justice." In addition, the participants mentioned that having spaces for gatherings where informal temporary coalitions could be formed to focus on specific issues would help assess if either better partnerships or different policy could drive the innovation as effectively as having new technologies. 3

\section{Lessons Learned:}

1. Respecting organizational culture. NPOs remain people and project driven. To advance an innovation agenda and disrupt the sector's business as usual, a better understanding of what motivates innovation is needed. If the sector perceives "space" as a key element, then the non-profit innovation policies must include "creating spaces for collaboration" alongside current suggestions such as "improving digital literacy" or "allocating a technology budget."

2. Being sensitive to nuances of adult education, maintaining flexible, human-centered

The International Journal of Information, Diversity, \& Inclusion, 4(2), 2020

ISSN 2574-3430, jps.library.utoronto.ca/index.php/ijidi/index

DOI: 
agenda and proactively managing energy in the room to maintain excitement. Stepping out of one's comfort zone can be difficult, and the role of hackathon organizers is to balance the discomfort of learning attitudes, stereotypes and biases with opportunities to nurture creativity as an ability to tolerate uncertainty in a changing social environment.

3. Being an ethnographer, and not underestimating the long-term value of the seed planted. The importance of recording conversations and documenting processes and best practices will be of benefit to participants as much as to organizers. Learning new skills (technical or otherwise) is just the top of the iceberg, as the ripple effects generated by MigrahackTO illustrated (e.g., new collaborations, emerging agendas).

\section{The Rationale}

In 2019, on the occasion of the 50th anniversary of the adoption of the Official Languages Act (which established English and French as the official languages of Canada), public consultations were held about modernizing the Act, particularly around access to justice, technological developments, and the inclusion of Indigenous languages, which were hitherto omitted from the Act (Office of the Commissioner of Official Languages, 2019). In policy making, public consultations are an important tool although they tend to reveal "an imperfect, contingent set of processes... between powerful institutions and the people they affect" (Johnson \& Howsam, 2018, p. 266). Because Canadian NPOs have been historically discouraged from advocacy-related activities while encouraged to adopt "neutrality" as a means of active political distancing, the sector envisions itself as neutral at its best or silent at its worst (Mule \& Desantis, 2017; Yundt, 2012). However, the increased pressures of fast changing demographics, migration, precarious employment markets, and worsening climate change is slowly altering the sector conviction about benefits of political neutrality while increasing its engagement with assessments of legislative or policy frameworks in respect to the needs of their users (Ontario Nonprofit Network, 2019). In this context, policy hackathons are still viewed as a novel approach to gathering various players to talk about policy matters in an effort to compensate for inadequate consultation mechanisms.

As a settlement sector agency whose work centers on language rights, MCIS sought to explore the issue of language justice gaps (of those languages not being captured by the Official Languages Act). To facilitate a broader conversation about how more inclusive and just language access infrastructure could be built whereby all languages, people, data, evidence, technology, processes, and policies could be adequately represented, MCIS partnered with the Policy Innovation Initiative, a student-run body, part of the Munk School of Global Affairs and Public Policy at the University of Toronto, to organize a policy hackathon. The aim of the language policy hackathon was to explore a range of issues, from "how do we engage community leaders with the health service providers to build trusted, culturally sensitive services" to "how do we increase newcomers and immigrant voter turnout" (Trinaistic \& Shahzad, 2019).

\section{The Process}

The Language Policy Hackathon was attended by over 60 participants from the settlement, NPO, and government sectors as well as from academia and by citizens and community champions referred by settlement agencies. The advance preparation for the event was extensive and included educational sessions about policy design and citizen participation conducted through

The International Journal of Information, Diversity, \& Inclusion, 4(2), 2020

ISSN 2574-3430, j.jps.library.utoronto.ca/index.php/ijidi/index

DOI: 
webinars, lunch-and-learn sessions, and a curated list of videos and reading materials. In addition, a number of assessment surveys and one-on-one interviews with service users were completed prior to the event, over a span of nine weeks. Community champions as well as interpreters and translators were compensated for the time they spent in preparing for and contributing to the event. At the beginning of the hackathon, the organizers provided a short session on problem definition, along with a brief history of access to language services in Canada to level the playing field and set the tone. Ideation and prototyping were embedded with facilitation of the empathy journey workshop, inclusive of interactive sessions to develop personas to map a number of language barrier journeys. Notetakers and facilitators were assigned to each table to capture the process and key conversations. Post event survey results and summaries of the day's proceedings were published and shared with all participants.

Table 2. Types of Audiences and Activities Undertaken Before, During and After Language Policy Hackathon

\section{Participants}

- MCIS staff participants

- Community members

- language professionals (interpreters, translators)

- NPOs - settlement sector

- Academia - policy students

- Government/ Policy makers

Pre-event

Survey and workshops/webinars

- Good Policy Making

- Hard Evidence for Policy Making

- Soft Evidence for Policy Making

- Canadian Language Policies

\begin{tabular}{|c|c|}
\hline \multicolumn{2}{|c|}{ Event } \\
\hline $\begin{array}{l}\text { Morning } \\
\text { - Introduction: presentation } \\
\text { - Empathy journey: workshop } \\
\text { - Empathy journey: participation: } \\
\quad \text { forming teams }\end{array}$ & $\begin{array}{l}\text { Afternoon } \\
\text { - Work on projects overseen by mentors } \\
\text { - Voting on policy solutions and wrap } \\
\quad \text { up }\end{array}$ \\
\hline \multicolumn{2}{|c|}{ Post-event } \\
\hline \multicolumn{2}{|c|}{$\begin{array}{l}\text { - } \quad \text { Post-event survey } \\
\text { - Creation of final report and recommendations }\end{array}$} \\
\hline
\end{tabular}

\section{The Shift}

As MCIS was contemplating the role of settlement NPOs in facilitating more symmetrical and reciprocal relationships with government/policy makers and the end users, the "shift" was

The International Journal of Information, Diversity, \& Inclusion, 4(2), 2020

ISSN 2574-3430, jps.library.utoronto.ca/index.php/ijidi/index

DOI: 
initially meant to help the organizers to be more cognizant of their positionality and of the importance of shared authority. Indeed, as considerably more time was invested in orienting participants about the work about to be done, the participants were equally more comfortable with seeing themselves as experts with meaningful "lived experiences" that could be contributed toward larger conversation about policy improvement (for which compensation was deemed reasonable in light of their time). There was, therefore, an observable shift toward richer conversations when it came to tackling policy matters, as well as more openness when "what if" exercises were implemented. The participants explicitly shared personal excitement about being given the opportunity to engage with and provide critique on reading materials and policy documents. Further, they perceived the empathy journey conducted during the event as validation of their own experiences. Finally, the note takers also observed that as the hypothetical personas came fully alive, the language became more spontaneous and simplified. As one policymaker participant stated in a follow-up interview, "the language policy hackathon gave me more than I could imagine about how one accesses language services, and has changed the way I see the world."

\section{Lessons Learned:}

1. Holding the space for relevant policy discussions; committing to civic education through participation: For the majority of the participants, the greatest value of a hackathon was in participating ("participating in political advocacy action"; "feeling more knowledgeable about policy innovation").

2. Providing spaces for creativity and hope: $39 \%$ of the participants (a percentage equally distributed across all groups) commented on the importance of "creating an atmosphere where people with different skill sets can brainstorm together, create partnerships and learn about challenges" and of "inspiring participants to consider the art of what is possible and think and imagine forward-thinking solutions."

3. A space for self-reflection and growth: Participants had the scope to reflect on citizenship, justice, and (language) access, as well as on the role-and indeed responsibility-of the NPO sector in being innovative and supporting civic society at large.

\section{Conclusion}

Across Canada, the different levels of government are seeking ways to harness the power of communities to innovate, transform society, and improve economic opportunities both in the local and global markets. An engagement of this scope and ambition demands that citizens be viewed as assets and resources with lived experiences and localized knowledge that can greatly contribute to improving public governance. In addition, NPOs that are increasingly mandated to innovate ought to be provided with the resources to do so. In an interview with Baker (2018), Adam Kahane notes that the idea that "social innovation is primarily about thinking up something new is only occasionally true. What it's more often about is an alliance or a group being willing to do together something that had already been thought of" (para 7). The essence of NPO innovation is indeed an attempt to disrupt the way that "things are done" and remove the entry barriers for atypical participants, especially marginalized ones, when it comes to conversations about power and influence. When atypical ceases to be a novelty and even a temporary power balance is established, the space and incentive for a larger shift to happen is created-one in which participants could see themselves as an active instrument of contributing to change they

The International Journal of Information, Diversity, \& Inclusion, 4(2), 2020

ISSN 2574-3430, jps.library.utoronto.ca/index.php/ijidi/index

DOI: 
are competent and capable of undertaking. In this sense, civic, policy, or community hackathons are both spaces and instruments of rapid and equitable innovation that leverage service users' input with appropriate technology and that are permeated by an attitude of open mindedness, positive practicality, and radical inclusion.

\section{Acknowledgements}

I thank MCIS Language Solutions, particularly Latha Sukumar and Veronica Costea, for their support, including early revisions of this article. I also thank Sreyoshi Bose for her comments, edits and construction of tables. The assistance provided by Craig Carter-Edwards and Marco Campana helped tremendously with achieving clarity about non-profit innovation. Finally, I wish to extend my special thanks to Prof. Nadia Caidi for her ongoing encouragement and support as well as edits and comments throughout.

\section{Endnotes}

1 For more information about interviews and survey, see For more information, see https://www.migrahackto.com For more information about interviews and survey, see https://sencanada.ca/content/sen/committee/421/CSSB/Reports/CSSB_Report_Final_e.pdf and

https://docs.google.com/document/d/1_aUlSZDk7WOj4kv088KdPMOKr22B56HmHxfpWg3ORDk/ edit?usp=sharing

2 See www.migrahack.org or https://jsk.stanford.edu/news-notes/2014/claudia-nunez-breakroutine-take-the-first-step-lose-fear/for information on its origin and context.

3 For more information, see https://el3646.wixsite.com/website.

\section{References}

Baker, S. (2018, January 9). Countless rebellions: Challenging the terms of collaboration: Interview with Adam Kahane. McConnell Foundation. https://mcconnellfoundation.ca/interview/adam-kahane/

Blumberg, M. (2018, February 1). Senate appoints special committee on the charitable sector to look at laws and policies and impact. Global Philanthropy Canada. https://www.globalphilanthropy.ca/blog/senate_appoints_special_committee_on_the_ charitable_sector_to_look_at_laws

Cave, J., Aitken, K., \& Lalande, L. (2017). Bridging the gap: Designing a Canadian what works centre. Mowat Research, 155, 1-41.

https://munkschool.utoronto.ca/mowatcentre/bridging-the-gap/

Cave, J., Gyateng, T., Lalande, L., \& Lumley, T. (2018). Collaborating for greater impact: Building an integrated data ecosystem. Mowat Research 161, 1-35. https://mowatcentre.ca/collaborating-for-greater-impact/

The International Journal of Information, Diversity, \& Inclusion, 4(2), 2020

ISSN 2574-3430, jps.library.utoronto.ca/index.php/ijidi/index

DOI: 
Employment and Social Development Canada. (2018). Inclusive innovation, new ideas and new partnerships for stronger communities, social innovation and social finance strategy co-creation steering group. https://www.canada.ca/en/employment-socialdevelopment/programs/social-innovation-social-finance/reports/recommendationswhat-we-heard.html

European Commission. (2017). Quality of public administration - A toolbox for practitioners, theme 1: Policy-making, implementation and innovation. European Commission. https: / /ec.europa.eu/social/ main.jsp?catld=738\&langld=en\&publd=8055\&type=2\&furth erPubs=no

Government of Canada. (2018). Fall economic statement. https://budget.gc.ca/feseea/2018/docs/statement-enonce/toc-tdm-en.html

Innovation, Science and Economic Development Canada (ISED). (2019). Building a nation of innovators. https://www.ic.gc.ca/eic/site/062.nsf/eng/h_00105.html

Johnson, G.F. \& Howsam, R. (2018). Can consultation ever be collaborative? Policy Design and Practice, 1(4), 253-268. https://doi.org/10.1080/25741292.2018.1531583

Lalande, L., Lumley, T., Nilson, C., Hughes, J., Corley, C., McFee, D., \& Taylor-Collins, E. (2018, November 12). Supporting evidence-informed policymaking and service delivery in Canada's non-profit sector. The Philanthropist. https://thephilanthropist.ca/2018/11/supporting-evidence-informed-policymakingand-service-delivery-in-canadas-non-profit-dector/

MCIS Language Solutions. (2018). MigrahackTO 2018 report. https://www.mcislanguages.com/website/wp-content/uploads/2018/04/MigrahackTOReport-2018-Final-.pdf

Mule, N. J., \& Desantis, G. C. (Eds.). (2017). The shifting terrain: Nonprofit policy advocacy in Canada. McGill-Queen's University Press.

OECD/Eurostat. (2019). Oslo manual 2018: Guidelines for collecting, reporting and using data on innovation. (4th ed.). OECD Publishing. https://doi.org/10.1787/9789264304604-en

Office of the Commissioner of Official Languages. (2019). Public consultation on the modernization of the Official Languages Act. https://www.cloocol.gc.ca/en/language-rights/act/public-consultations-modernization

Ontario Nonprofit Network. (2015). Toward a data strategy for the Ontario nonprofit sector. https://theonn.ca/wp-content/uploads/2015/07/Towards-a-Data-Strategy-for-OntarioNonprofit-Sector_ONN_Final_2015-07-13.pdf

Senate Canada. (2019). Catalyst for change: A roadmap to a stronger charitable sector. https://sencanada.ca/content/sen/committee/421/CSSB/Reports/CSSB_Report_Final_ e.pdf

Trinaistic, E. (2018, July 4). Hackathons: Non-profit methodology for learning and innovation. Linkedln Publishing. https://www.linkedin.com/pulse/hackathons-non-profit-

The International Journal of Information, Diversity, \& Inclusion, 4(2), 2020

ISSN 2574-3430, jps.library.utoronto.ca/index.php/ijidi/index

DOI: $10.33137 /$ ijidi.v4i2.34035 
methodology-learning-innovation-trinaistic

Trinaistic, E., \& Shahzad, N. (2019). Language policy hackathon report. https://pub.lucidpress.com/languagepolicyhackathon2019/\#z 1XqUtRj-a2

Yundt, H. (2012, October 1). The politics of advocacy: Are charities apathetic or afraid? Charity Village. https://charityvillage.com/cms/content/topic/the_politics_of_advocacy_are_charities _apathetic_or_afraid\#.XZZWpy5KiUl

Eliana Trinaistic (elianatrinaistic@gmail.com) has been in the role of Social Impact Manager with MCIS Language Solutions for nearly seven years. Apart from working at MCIS, Eliana, is engaged in researching and writing about digital rights, inclusion, and purpose at work in the non-profit sector, and is involved as consultant and coach in women-led social enterprises in Croatia. Eliana's prior professional experience includes work with libraries and cultural societies on oral history projects, knowledge management roles, adult education, and management of volunteers.

Eliana has a master's degree in Information and Environmental Sciences, (iSchool, University of Toronto) with a focus on libraries and sustainability. She is a certified Executive Coach and is currently focusing on research of digital cooperatives and social purpose economy. Eliana has presented on issues like the role of language professionals in "smart cities," community hackathons, and language rights advocacy at seminars and conferences across Canada and internationally. She has been contributing to several community initiatives and advisory groups, addressing needs of people with language barriers, community-led archives, and collaborative technology projects.

The International Journal of Information, Diversity, \& Inclusion, 4(2), 2020

ISSN 2574-3430, jps.library.utoronto.ca/index.php/ijidi/index

DOI: $10.33137 /$ ijidi.v4i2.34035 